\title{
Proceeding Paper \\ Comparative Study of Optimization Techniques Based PID Tuning for Automatic Voltage Regulator System ${ }^{\dagger}$
}

\author{
Mohamed Cherif Rais ${ }^{1}$, , Fatma Zohra Dekhandji ${ }^{1}$, Abdelmadjid Recioui ${ }^{1}$, Mohamed Sadek Rechid ${ }^{2}$ \\ and Lahcen Djedi ${ }^{2}$
}

check for

updates

Citation: Rais, M.C.; Dekhandji, F.Z.; Recioui, A.; Rechid, M.S.; Djedi, L. Comparative Study of Optimization Techniques Based PID Tuning for Automatic Voltage Regulator System. Eng. Proc. 2022, 14, 21. https:// doi.org/10.3390/engproc2022014021

Academic Editor: Hamid Bentarzi

Published: 11 February 2022

Publisher's Note: MDPI stays neutral with regard to jurisdictional claims in published maps and institutional affiliations.

Copyright: (C) 2022 by the authors. Licensee MDPI, Basel, Switzerland. This article is an open access article distributed under the terms and conditions of the Creative Commons Attribution (CC BY) license (https:// creativecommons.org/licenses/by/ $4.0 /)$.
1 Signals and systems Laboratory, Institute of Electrical and Electronic Engineering, University M'Hamed Bougara of Boumerdes, Boumerdes 35000, Algeria; fzdekhandji@univ-boumerdes.dz (F.Z.D.); a.recioui@univ-boumerdes.dz (A.R.)

2 Institute of Electrical and Electronic Engineering, University M'Hamed Bougara of Boumerdes, Boumerdes 35000, Algeria; medsadek072@gmail.com (M.S.R.); lahcendjedi6298@gmail.com (L.D.)

* Correspondence: m.rais@univ-boumerdes.dz

+ Presented at the 1st International Conference on Computational Engineering and Intelligent Systems, Online, 10-12 December 2021.

\begin{abstract}
A comparative study is performed to design an optimal PID controller for an automatic voltage regulator system using different optimization techniques. The presented approaches are referred to as particle swarm optimization (PSO) algorithm, cuckoo search optimization (CSO) algorithm, moth flame optimization (MFO) algorithm, water cycle optimization (WCO) algorithm, teaching-learning-based optimization (TLBO) algorithm, and hill climbing optimization (HCO) algorithm. Transient response parameters, which are rise time $\mathrm{Tr}$, settling time $\mathrm{Ts}$, and percentage overshoot $\mathrm{Mp}$, are used as comparison criteria. The integral time absolute error ITAE is the used performance index. All the proposed optimization techniques improved the transient response of the AVR system in a different way and gave good preliminary results.
\end{abstract}

Keywords: optimization techniques; AVR system; PID tuning

\section{Introduction}

In an electrical power system, the AVR is used to maintain the terminal voltage magnitude of a generator [1]. Controlling the generator excitation keeps the magnitude of this voltage at a specific level. In general, traditional tuning methods such as Ziegler-Nichols $(\mathrm{ZN})$ and gain-phase margin make it difficult to find optimal controller parameters [2]. As a result, several optimization techniques for tuning controller parameters have been proposed. Some of these optimization techniques which used as tuning methods to improve the performance of the (PID) controller are particle swarm optimization (PSO) $[3,4]$, cuckoo search optimization (CSO) algorithm [5,6], moth flame optimization (MFO) algorithm [7,8], water cycle optimization (WCO) algorithm [9,10], teaching-learning-based optimization (TLBO) [11-13]. Hill climbing optimization (HCO) algorithm [14] is tested for the first time in the AVR system in this work. Fractional order PID (FOPID) [15], PID-acceleration (PIDA) [16], gray PID (GPID) [17], and fuzzy logic PID (FLPID) [18] are some of the other controller types used to improve the dynamic response of AVR systems in the literature.

The rest of this paper is organized as follows. Section 2 describes the AVR system and its block diagram model with the used values. Section 3 describes the implementation of the proposed optimizations techniques and provides comparison of the results of the numerical simulations. Section 4 concludes the paper with a summary of the research's main findings.

\section{AVR System}

The primary consumer demand in the power system is the quality of electrical energy. In addition, the majority of equipment is designed to operate at predetermined voltage and 
frequency levels, since the interaction between voltage control and frequency control in a power generation system is usually weak enough that they can be analyzed separately. Moreover, a small variation in voltage can result in a significantly large variation in reactive power flow, which can result in massive power loss and, as a result, economic loss. To avoid this, the automatic voltage regulator (AVR) system is used in power generation sites to ensure voltage stability at the generator terminal via the excitation system. An AVR system and its model are shown in Figure 1.

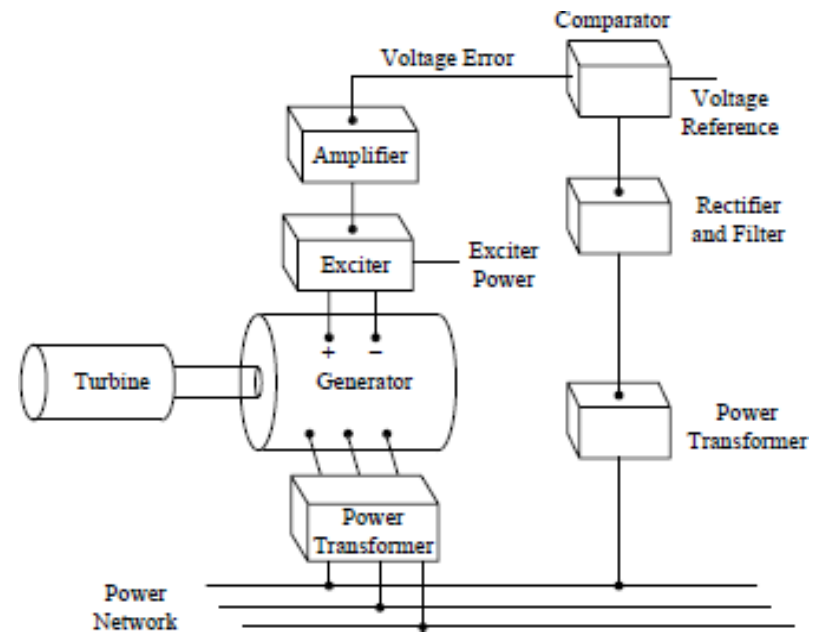

(A)

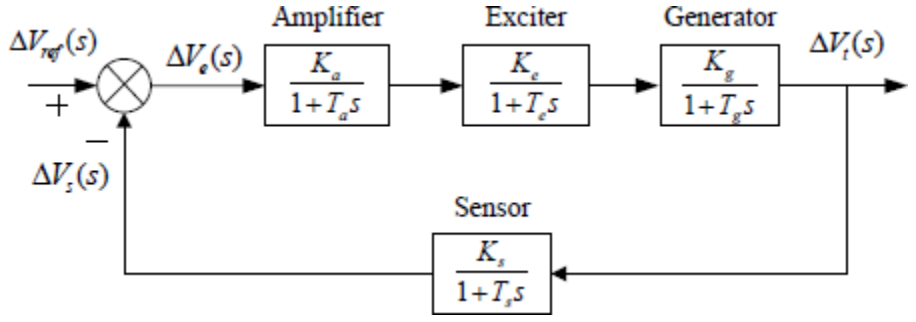

(B)

Figure 1. (A) AVR system. (B) Block diagram of the AVR system.

$\Delta \operatorname{Vref}(\mathrm{s}), \Delta \mathrm{Vs}(\mathrm{s}), \Delta \mathrm{Ve}(\mathrm{s})$, and $\Delta \mathrm{V}_{\mathrm{t}}(\mathrm{s})$ are the reference input voltage, sensor output voltage, error voltage, and generator terminal voltage, respectively. Table 1 shows the boundary values of AVR system components as well as the values used in the AVR system.

Table 1. Boundary values of the AVR system.

\begin{tabular}{ccc}
\hline Model & Parameter Ranges & Used Values in AVR System \\
\hline \multirow{2}{*}{ Amplifier } & $10 \leq \mathrm{Ka} \leq 40$ & $\mathrm{KA}=10$ \\
& $0.02 \leq \mathrm{Ta} \leq 0.1$ & $\mathrm{TA}=0: 1$ \\
\hline \multirow{2}{*}{ Exciter } & $1 \leq \mathrm{Ke} \leq 2$ & $\mathrm{Ke}=1$ \\
& $0.4 \leq \mathrm{Te} \leq 1$ & $\mathrm{Te}=0: 4$ \\
\hline \multirow{2}{*}{ Generator } & $1 \leq \mathrm{Kg} \leq 2$ & $\mathrm{Kg}=1$ \\
& $1 \leq \mathrm{Tg} \leq 2$ & $\mathrm{TG}=1$ \\
\hline \multirow{2}{*}{ Sensor } & $\mathrm{Kr}=1$ & $\mathrm{KR}=1$ \\
& $0.001 \leq \mathrm{Tr} \leq 0.006$ & $\mathrm{TR}=0: 01$ \\
\hline
\end{tabular}

The uncontrolled system transfer function is:

$$
G(s)=\frac{0.1 s+10}{0.0004 s^{4}+0.0454 s^{3}+0.555 s^{2}+1.5 s+11}
$$

Although stable, the AVR system's step response is extremely oscillatory without a controller, as illustrated in Figure 2. 


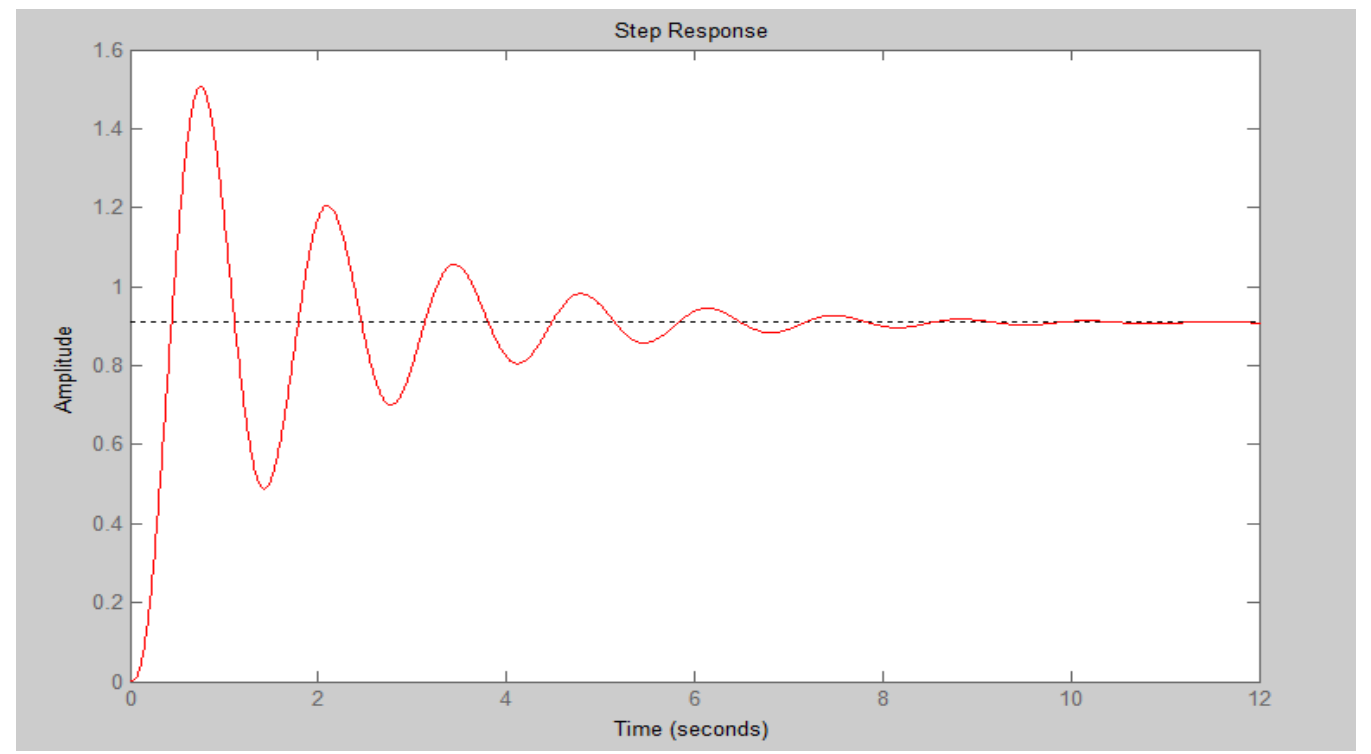

Figure 2. Step response of AVR system in the absence of a controller.

Table 2 summarizes the transient response parameters of the AVR system in the absence of the controller.

Table 2. Transient performance of the AVR system without controller.

\begin{tabular}{cccc}
\hline Rise Time (s) Tr & $\begin{array}{c}\text { Settling Time } \\
\mathbf{2 \%}(\mathbf{s}) \text { Ts }\end{array}$ & $\begin{array}{c}\text { Overshoot Mp } \\
\mathbf{( \% )}\end{array}$ & $\begin{array}{c}\text { Steday State Error } \\
\text { Ess }\end{array}$ \\
\hline 0.261 & 6.99 & 65.7 & 0.091 \\
\hline
\end{tabular}

These results show that by utilizing a PID controller, the transient response of the AVR system can be improved and the steady state error can be removed.

\section{Implementation of Proposed Optimization Techniques}

The primary goal of this work is to design and construct a high-performance PID controller for AVR systems in synchronous generators. The design challenge is stated as an optimization control problem, and the proposed optimization algorithms are used to find optimal controller parameters. Particle swarm optimization (PSO), cuckoo search optimization (CSO), moth flame optimization (MFO), water cycle optimization (WCO), teaching-learning-based optimization (TLBO), and hill climbing (HCO) have been tested, and a comparison has been carried out. The integral time absolute error (ITAE) is the performance index used in this work to examine and build the suggested OA-PID controller, which is given as

$$
\stackrel{T}{T} \text { Integral time absolute error ITAE }=\int_{0} t|e(t)| d t
$$

The block diagram of the AVR system with the proposed OA-PID controller is shown in Figure 3. 


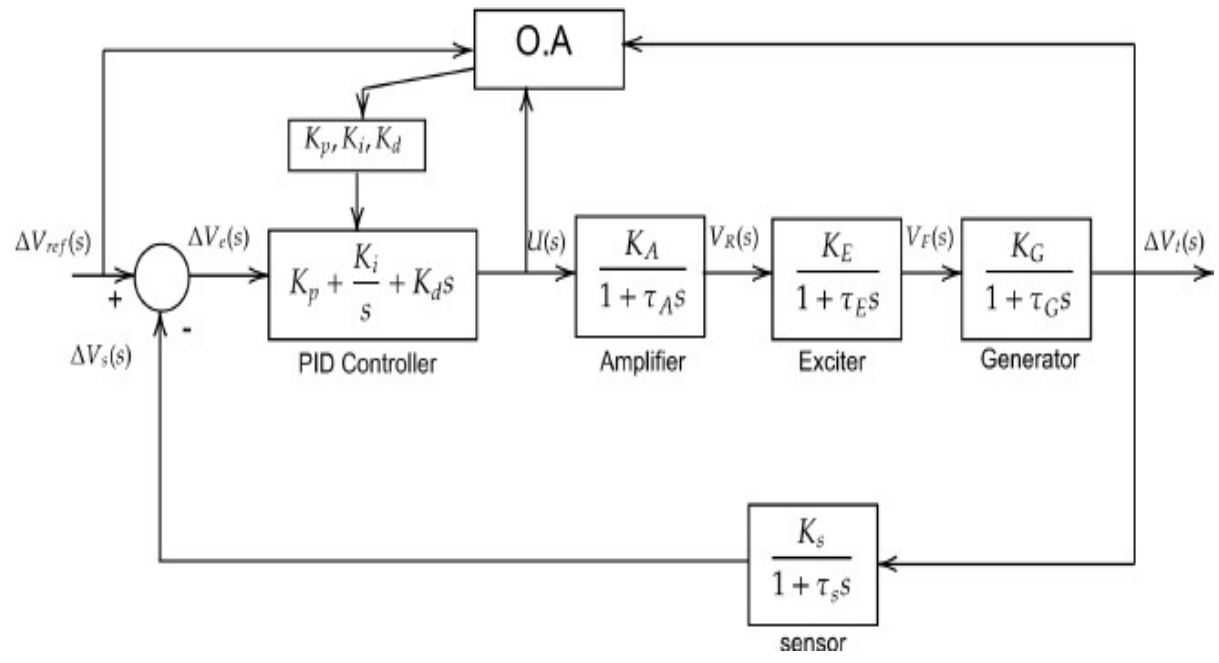

Figure 3. AVR system with proposed OA-PID Controller.

Table 3 shows the adjusted and optimal PID controller settings acquired by proposed optimization techniques and the transient response analysis results after the simulation procedure.

Table 3. Optimized PID parameters and transient response analysis results.

\begin{tabular}{ccccc}
\hline $\begin{array}{c}\text { Optimization } \\
\text { Technique }\end{array}$ & $\begin{array}{c}\text { Controller Parameters } \\
\text { Kp-Ki-Kd }\end{array}$ & Tr: $\mathbf{0 . 1} \rightarrow \mathbf{0 . 9}$ & Ts $+\mathbf{2} \%$ & Mp (\%) \\
\hline PSO-ITAE & $0.7027-0.5471-0.37852$ & 0.1969 & 1.3466 & 1.718 \\
\hline CSO-ITAE & $0.6999-0.54672-0.37904$ & 0.1967 & 1.3498 & 1.7266 \\
\hline MFO-ITAE & $1.5643-1.0713-0.5132$ & 0.1319 & 0.7518 & 22.7511 \\
\hline WCO-ITAE & $1.4802-1.0153-0.4809$ & 0.1386 & 0.7769 & 21.2312 \\
\hline TLBO-ITAE & $1.2298-1.8472-0.3944$ & 0.1623 & 0.8533 & 16.3603 \\
\hline HCO-ITAE & $0.5900-0.4200-0.2000$ & 0.3272 & 0.5131 & 0 \\
\hline
\end{tabular}

The comparative simulation results obtained for the terminal voltage step response of the AVR system with the different optimization techniques are shown in Figure 4.

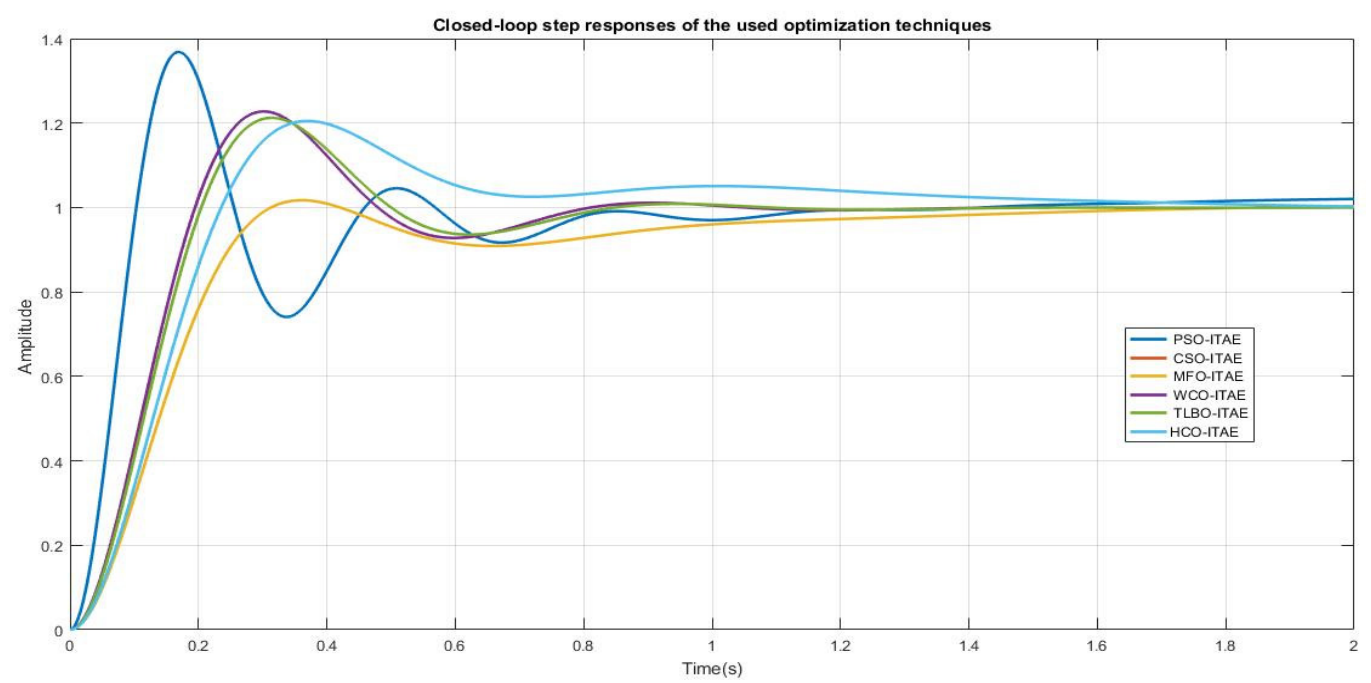

Figure 4. Terminal voltage response curves of the AVR system with various optimization techniques. 
It is evident from Figure 4 and Table 3 that the MFO, WCO, and TLBO techniques delivered a response with a high percentage overshoot and quicker rise time than the $\mathrm{PSO}, \mathrm{HCO}$, and CSO methods. On the other hand, the $\mathrm{HCO}$ technique yielded a system with no oscillation and rapid settling time compared to the other optimization techniques. Furthermore, the PSO and CSO performances are almost the same, producing a response with little overshoot and long settling time. The HCO tuned PID controller with the ITAE fitness function generates a superior control performance in terms of improved overshoot and settling time.

\section{Conclusions}

The main goal of this study is to design an optimal PID controller parameter for the AVR system using different optimization techniques. A comparison based on integral time absolute error ITAE performance index and transient response parameters was carried out. The most obvious finding to emerge from this study is that all optimization techniques have improved the system performance compared to the uncontrolled case. The second major finding was that each optimization algorithm improves some parameters and, at the same time, deteriorates another one. However, it is worth noting that the hill climbing (HCL) technique yields generally better results in terms of percentage overshoot and settling time. Finally, the current study has only examined one performance index and focused on transient analysis. A natural progression of this work is to analyze the system performance based on other objective functions and other stability criteria and consider a hybridization between best optimization techniques.

Author Contributions: Conceptualization, M.C.R.; methodology, F.Z.D.; software, M.S.R. and L.D.; validation, F.Z.D.; formal analysis, M.C.R.; investigation, M.C.R.; resources, M.S.R. and L.D.; data curation, M.C.R.; writing—original draft preparation, M.C.R.; writing—review and editing, F.Z.D., A.R.; visualization, M.C.R.; supervision, F.Z.D. All authors have read and agreed to the published version of the manuscript.

Funding: This research received no external funding.

Institutional Review Board Statement: Not applicable.

Informed Consent Statement: Not applicable.

Conflicts of Interest: The authors declare no conflict of interest.

\section{References}

1. Saadat, H. Power System Analysis; McGraw-Hill: New York, NY, USA, 1999.

2. Ogata, K. Modern Control Engineering, 4th ed.; Prentice-Hall: Upper Saddle River, NJ, USA, 2002.

3. Gaing, Z.-L. A particle swarm optimization approach for optimum design of pid controller in avr system. IEEE Trans. Energy Convers. 2004, 19, 384-391. [CrossRef]

4. Rahimian, M.; Raahemifar, K. Optimal pid controller design for avr system using particle swarm optimization algorithm. In Proceedings of the 2011 24th Canadian Conference on Electrical and Computer Engineering (CCECE), Niagara Falls, ON, Canada, 8-11 May 2011; pp. 337-340.

5. Yang, X.-S.; Deb, S. Cuckoo search via lévy flights. In Proceedings of the 2009 World Congress on Nature Biologically Inspired Computing (NaBIC), Coimbatore, India, 9-11 December 2009; pp. 210-214.

6. Bingul, Z.; Karahan, O. A novel performance criterion approach to optimum design of PID controller using cuckoo search algorithm for avr system. J. Frankl. Inst. 2018, 355, 5534-5559. [CrossRef]

7. Mirjalili, S. Moth-flame optimization algorithm: A novel nature-inspired heuristic paradigm. Knowl.-Based Syst. 2015, 89, 228-249. [CrossRef]

8. Dixit, A.; Lokhande, M.; Joshi, N. Optimization of automatic voltage regulator using moth flame optimization algorithm. Int. J. Eng. Dev. Res. 2016, 4, 367-371.

9. Eskandar, H.; Sadollah, A.; Bahreininejad, A.; Hamdi, M. Water cycle algorithm-A novel metaheuristic optimization method for solving constrained engineering optimization problems. Comput. Struct. 2012, 110-111, 151-166. [CrossRef]

10. Pachauri, N. Water cycle algorithm-based pid controller for AVR. COMPEL Int. J. Comput. Maths. Electr. Electron. Eng. 2020, 39, 551-567. [CrossRef]

11. Chatterjee, S.; Mukherjee, V. Pid controller for automatic voltage regulator using teaching-learning based optimization technique. Int. J. Electr. Power Energy Syst. 2016, 77, 418-429. [CrossRef] 
12. Abdelmadjid, R.; Khaled, D. Design of Standalone Micro-Grid Systems Using Teaching Learning Based Optimization. Alger. J. Signals Syst. 2017, 2, 75-85.

13. Bouaraki, M.; Abdelmadjid, R. Optimal placement of power factor correction capacitors in power systems using Teaching Learning Based Optimization. Alger. J. Signals Syst. 2017, 2, 102-109. [CrossRef]

14. Hill Climbing Algorithm in Artificial Intelligence. Available online: https://www.javatpoint.com/hill-climbingalgorithm-in-ai (accessed on 1 December 2021).

15. Lahcene, R.; Abdeldjalil, S.; Aissa, K. Optimal tuning of fractional order pid controller for avr system using simulated annealing optimization algorithm. In Proceedings of the 2017 5th International Conference on Electrical Engineering Boumerdes (ICEE-B), Boumerdes, Algeria, 29-31 October 2017; pp. 1-6.

16. Sambariya, D.K.; Paliwal, D. Design of PIDA controller using bat algorithm for AVR power system. Adv. Energy Power 2016, 6 , 1-6. [CrossRef]

17. Tang, Y.; Zhao, L.; Han, Z.; Bi, X.; Guan, X. Optimal gray PID controller design for automatic voltage regulator system via imperialist competitive algorithm. Int. J. Mach. Learn. Cyber. 2016, 7, 229-240. [CrossRef]

18. Al Gizi, A.J.H.; Mustafa, M.W.; Al-Geelani, N.A.; Alsaedi, M.A. Sugeno fuzzy PID tuning, by genetic-neutral for AVR in electrical power generation. J. Appl. Soft. Comput. 2015, 28, 226-236. [CrossRef] 